\title{
TECNOLOGIAS EMPREGADAS NO TRATAMENTO DE EFLUENTES DE LATICÍNIOS DO VALE DO RIO BRAÇO DO NORTE-SC
}

\author{
Marciel Dela Justina" \\ Aniela Pinto Kempka** \\ Everton Skoronski***
}

RESUMO: Associada à atividade produtiva de laticínios está o grande montante de efluentes gerados no processo de beneficiamento do leite. Pela complexidade de composição, variação nas taxas de produção e variação na própria composição do efluente gerado nesta atividade, a escolha de um sistema eficaz na remoção dos contaminantes ali presentes pode ser bastante complexa. Desta forma, com o presente estudo buscou-se apresentar as técnicas utilizadas em escala global para essa finalidade, e paralelamente traçar um perfil das tecnologias aplicadas pelas empresas de laticínios na região do Vale do rio Braço do Norte, sul de Santa Catarina, bem como demais aspectos relacionados à gestão ambiental dessas empresas. Após levantamento de dados, por meio de pesquisa de campo via questionário e avaliação documental, observou-se que as empresas dessa região aplicam predominantemente sistemas anaeróbios para remoção de matéria orgânica biodegradável, atingindo níveis de remoção dentro da legislação. Contudo, demais parâmetros analisados, como óleos e graxas, $\mathrm{pH}$ e sólidos sedimentáveis apresentaram alguns valores fora do preconizado pelos órgãos ambientais. A gestão ambiental das empresas é realizada predominantemente por pessoal terceirizado, deixando evidente a falta de pessoal interno, tecnicamente capacitado para atuar nas empresas.

PALAVRAS-CHAVE: Gestão ambiental; Monitoramento ambiental; Controle da poluição hídrica.

\section{TECHNOLOGIES IN THE TREATMENT OF DAIRY EFFLUENTS IN THE VALE DO RIO BRAÇO DO NORTE, BRAZIL}

ABSTRACT: Great amounts of effluents produced in dairy processing are associated to dairy production activities. Choosing an efficient system in the removal of

Mestrando em Ciências Ambientais pelo Programa de Pós-graduação em Ciência e Tecnologia de Alimentos (PPGCTA/UDESC), Brasil.

** Doutora em Engenharia Química; Docente permanente e Coordenadora do Programa de Pós-graduação em Ciência e Tecnologia de Alimentos (PPGCTA/UDESC), Brasil. E-mail: aniela@ceo.udesc.br

*** Universidade do Estado de Santa Catarina, Departamento de Engenharia Ambiental, Laboratório de Tratamento de Águas e Resíduos, Brasil. 
contaminants may be a highly complex process due to the composition, variation in production rates and the effluent's composition. Current paper provides the techniques employed to this end and, at the same time, delineate the profile of technologies applied by dairy factories in the region Vale do rio Braço do Norte, in the south of the state of Santa Catarina, Brazil, coupled to other aspects related to the dairies' environmental management. Data, retrieved by a questionnaire and document evaluation, showed that the region's dairy establishments predominantly apply anaerobic systems for the removal of biodegradable organic matter, with removal rates complying with legislation. However, other parameters, such as oils, fats, $\mathrm{pH}$ and sediment solids had higher rates than those stipulated by environmental organs. The firms' environmental management is largely outsourced; in other words, they lack proper personnel technically capacitated for such work.

KEY WORDS: Environmental management; Environmental monitoring; Control of water pollution.

\section{INTRODUÇÃO}

Santa Catarina é o sexto maior industrializador de leite em nível nacional, com 567,8 milhões de litros processados no primeiro trimestre de 2015, apresentando um aumento de 10,2\% em comparação com o mesmo período de 2014 (IBGE, 2015). O Estado obteve um incremento de $190,9 \%$ em sua produção leiteira no período de 2000 a 2013 (EPAGRI/CEPA, 2015). No ano de 2010, o Estado contava com 591 empresas atuantes no setor de produção de laticínios (SEBRAE, 2013). Segundo a Epagri/Cepa (2015), em 2013, a região Sul do Estado respondia por 8,8\% da produção estadual (257,4 milhões de litros no ano), sendo a segunda região com maior montante de leite produzido, ficando apenas atrás da região Oeste, que responde por $73,6 \%$ do total.

Uma das principais características da indústria de laticínios é a elevada geração de efluentes. Para cada litro de leite processado nas plantas industriais de laticínios são gerados de 02 a 02 litros e meio de efluente (DVARIONIENE; KRUOPIENE; STANKEVICIENE, 2012). As principais fontes de efluentes neste ramo industrial são: lavação de linhas de transporte do leite, equipamentos, caminhões, silos e também os erros de procedimento podendo ser de ordem operacional ou 
falhas de equipamentos (DEMIREL; YENIGUN; ONAY, 2005). O soro gerado no processo também é importante fonte de efluentes em plantas beneficiadoras de leite. Para cada litro de leite de vaca processado na produção de queijo é gerado 0,873 litro de soro, sendo este considerado o poluente mais importante da indústria de laticínios, tanto pela elevada carga orgânica quanto pelo volume gerado (CARVALHO; PRAZERES; RIVAS, 2013).

No processamento de leite para produção do queijo o efluente gerado apresenta DQO variando de 0,8 a 102 g.L $\mathrm{L}^{-1}$ e DBO entre 0,6 e 60 g.L $\mathrm{L}^{-1}$. Esta demanda por oxigênio é atribuída principalmente à presença de gordura e lactose no efluente. Além de gordura e carboidratos, ocorrem compostos nitrogenados presentes em formas orgânicas (proteínas, ureia, ácidos nucleicos) ou sob a forma de íons: $\mathrm{NH}_{4}^{+}$, $\mathrm{NO}_{2} ; \mathrm{NO}_{3}$. Também há ocorrência de fósforo, como ortofosfato, polifosfato e em formas orgânicas. A presença de sólidos suspensos origina-se principalmente a partir de leite coagulado, massa de queijo e ingredientes flavorizantes. Observa-se também uma ampla variação de pH de 3,3 a 9,0 (CARVALHO; PRAZERES; RIVAS, 2013).

Águas residuais da indústria de laticínios são tratadas por vias físicoquímicas e microbiológicas, sendo que pelo custo de reagentes e da pobre remoção de DQO solúvel por vias físico-químicas, os processos biológicos são geralmente preferidos (DEMIREL; YENIGUN; ONAY, 2005). O grau de tratamento a dar-se aos efluentes depende principalmente de dois fatores: a qualidade do efluente antes de ser lançado ao corpo receptor e a legislação ambiental vigente e aplicável à região de despejo (DEZOTTI, 2008).

De modo geral, o tratamento de efluentes pode ser dividido em três etapas, sendo elas: pré-tratamento/tratamento primário, tratamento secundário e tratamento terciário. O pré-tratamento e tratamento primário removem os contaminantes presentes no efluente principalmente em virtude de suas características físicas, como tamanho de particulados e diferença entre densidade de fases. Desta forma agem as grades, peneiras, desarenadores e caixas de gordura (DEZOTTI, 2008).

Tanques de equalização devem ser utilizados em virtude das grandes variações existentes tanto nas taxas de geração quanto nas características físicoquímicas do efluente gerado em indústrias como as de laticínios. A sua utilização 
serve para fornecer uniformidade ao efluente destinado para as etapas posteriores de tratamento, tanto em relação às taxas de alimentação do sistema quanto às suas características físico-químicas (BABATOLA et al., 2011).

A flotação por ar dissolvido (FAD) é uma boa alternativa de tratamento primário quando há formação de emulsão no efluente. A FAD é uma operação utilizada para remoção de coloides, proteínas e óleos dispersos e emulsificados em água. (BABATOLA et al., 2011). O envio de lipídios para o tratamento secundário é problemático, uma vez que os ácidos graxos gerados na hidrólise de gorduras inibem a ação das bactérias metanogênicas em sistemas anaeróbios (DEMIREL; YENIGUN; ONAY, 2005).

O tratamento secundário destina-se à remoção de matéria orgânica por meio da degradação biológica desses compostos, que são transformados em moléculas mais simples como $\mathrm{H}_{2} \mathrm{O}, \mathrm{CO}_{2}, \mathrm{CH}_{4}, \mathrm{NH}_{3}$, dentre outros (DEZOTTI, 2008).

O tratamento biológico aeróbio convencional de efluentes de laticínios geralmente emprega tecnologias como lodos ativados, filtros biológicos, lagoas aeradas ou uma combinação destes, sendo que os reatores de batelada sequencial (RBS) têm se mostrado promissores (SHETE; SHINKAR, 2013). Um inconveniente neste tipo de tratamento é a grande produção de lodo biológico (DEZOTTI, 2008).

Pelo processo anaeróbio, a matéria orgânica é transformada por microrganismos facultativos ou estritamente anaeróbios em metano (60 a 70\%) e dióxido de carbono (30 a 40\%), além de outros componentes minoritários (DEZOTTI, 2008). Por não necessitar de aeração, pela baixa quantidade de lodo gerado, baixo consumo de energia, baixa demanda de área, além de potencial para geração de energia esse processo apresenta vantagens sobre as vias aeróbias (SHETE; SHINKAR, 2013). Alguns exemplos desses sistemas são os filtros anaeróbios, reatores anaeróbios em batelada sequencial, além dos reatores de circulação interna derivados do sistema UASB que permitem tanto o tratamento de efluentes com baixa carga orgânica, baixo tempo de retenção, quanto efluentes muito carregados com elevadas taxas de alimentação (DEMIREL; YENIGUN; ONAY, 2005). Sistemas de lagoas anaeróbias, os mais simples, apresentam eficiência de remoção de matéria orgânica em torno de 50 a $60 \%$, portanto devem ser combinados a outros sistemas de tratamento (DEZOT'TI, 2008). 
O tratamento terciário visa remover contaminantes que não tenham sido removidos nas etapas anteriores de tratamento, aplicando tanto processos biológicos para remoção de nutrientes quanto processos físico-químicos como filtração e adsorção (DEZOTTI, 2008).

Processos para completa remoção de nutrientes ocorrem por meio da conjugação entre etapas aeróbias e anaeróbias do tratamento. Estudos recentes têm sido realizados visando à remoção de carbono, nitrogênio e fósforo em uma única etapa de tratamento. Desta forma um sistema denominado "Upflow aerobicanoxic floculated sludge bioreactor (UAASB)" tem atingido este objetivo em escala laboratorial, apresentando remoção de $71 \%$ para DQO, 95\% para nitrogênio total e 96,5\% para fósforo (AMINI et al., 2013). Os processos de oxidação avançada têm sido considerado uma boa alternativa no tratamento de efluentes complexos como os de laticínios, podendo ser utilizados como pré-tratamento, aumentando a biodegradabilidade, pós-tratamento ou até como etapa única (MENDES; ZIZAS; FARIA, 2014).

Desta forma, diante de todas as formas de tratamento apresentadas anteriormente, o presente trabalho objetivou traçar um perfil das tecnologias utilizadas para tratamento de efluentes pelas indústrias de laticínios na região do vale do rio Braço do Norte - SC, trazendo informações sobre sua eficiência operacional. Além dos aspectos operacionais relativos ao tratamento dos efluentes, o trabalho também buscou verificar aspectos da gestão ambiental das empresas relacionados à gestão dos seus recursos hídricos.

\section{MATERIAL E MÉTODOS}

A região do vale do rio Braço do Norte localiza-se na bacia hidrográfica do rio Tubarão e Complexo Lagunar, formando uma das sub-bacias do rio Tubarão, no sul de Santa Catarina. É composta pelos municípios de Anitápolis, Santa Rosa de Lima, Rio Fortuna, Braço do Norte, São Ludgero e Grão Pará. A sub-bacia do rio Braço do Norte, que dá nome à região estudada, ocupa uma área de $1.756,16$ km² do total de $5.959,97 \mathrm{~km}^{2}$ da bacia hidrográfica do rio Tubarão. O rio Braço do Norte 
é um dos principais afluentes do rio Tubarão, juntamente com o rio Capivari, tendo sua nascente localizada no município de Anitápolis e atravessando os municípios de Santa Rosa de Lima, Rio Fortuna, Braço do Norte e São Ludgero, onde deságua no rio Tubarão. Ao longo de sua extensão, recebe cargas poluidoras advindas de diferentes atividades como agrícolas, agropecuárias, especialmente suinocultura e bovinocultura de corte e leite, e agroindustriais.

Para coleta de dados inicialmente realizou-se um levantamento sobre as empresas do ramo de laticínios presentes na região delimitada para realização do estudo, junto à Companhia Integrada de Desenvolvimento Agrícola de Santa Catarina - Cidasc.

Em seguida foram realizadas visitas às empresas para aplicação de questionários e realização de consultas documentais buscando-se informações sobre montante de efluente gerado, etapas de tratamento a que estes efluentes são submetidos, eficiência obtida na remoção dos contaminantes presentes e parâmetros físico-químicos utilizados para realização do monitoramento das condições de lançamento dos despejos.

Foram obtidas também informações sobre a gestão ambiental das empresas quanto à existência de pessoal qualificado na operação das estações de tratamento dos efluentes, monitoramento das condições ambientais de despejo dos mesmos e quanto a iniciativas de reúso da água tratada.

\section{RESULTADOS E DISCUSSÃO}

\subsection{TECNOLOGIAS EMPREGADAS NO TRATAMENTO DOS EFLUENTES}

Pelo levantamento realizado apontou-se a existência de 14 empresas do ramo de laticínios na região estudada. As principais tecnologias empregadas no tratamento dos efluentes encontram-se descritas no Quadro 1: 
Quadro 1. Tecnologias empregadas no tratamento dos efluentes pelas empresas estudadas

\begin{tabular}{|c|c|c|c|}
\hline Empresa & $\begin{array}{c}\text { Pré-tratamento/ tratamento } \\
\text { primário }\end{array}$ & $\begin{array}{l}\text { Tratamento } \\
\text { secundário }\end{array}$ & Vazão de trabalho \\
\hline A & $\begin{array}{c}\text { Gradeamento; caixa de } \\
\text { gordura; tanque de decantação. }\end{array}$ & $\begin{array}{l}\text { Filtro anaeróbio; } \\
\text { sumidouros. }\end{array}$ & $\begin{array}{l}\text { Projeto: } 20 \mathrm{~m}^{3} \cdot \mathrm{d}^{-1} \\
\text { Operação: } 10 \mathrm{a} \\
\mathrm{m}^{3} \cdot \mathrm{d}^{-1}\end{array}$ \\
\hline B & $\begin{array}{c}\text { Gradeamento; caixa de } \\
\text { gordura; tanque de decantação. }\end{array}$ & $\begin{array}{l}\text { Lagoa anaeróbia; duas } \\
\text { lagoas facultativas. }\end{array}$ & Projeto: $45 \mathrm{~m}^{3} \cdot \mathrm{d}^{-1}$ \\
\hline $\mathrm{C}$ & $\begin{array}{l}\text { Gradeamento; caixa de } \\
\text { gordura; tanque séptico/ } \\
\text { decantador. }\end{array}$ & $\begin{array}{l}\text { Lagoa anaeróbia; lagoa } \\
\text { facultativa. }\end{array}$ & N.I.* \\
\hline $\mathrm{D}$ & $\begin{array}{l}\text { Gradeamento; caixa de } \\
\text { gordura; decantador. }\end{array}$ & Lagoa aerada. & $\begin{array}{l}\text { Projeto: } 20 \mathrm{~m}^{3} \cdot \mathrm{d}^{-1} \\
\text { Operaçãa: } 15 \mathrm{~m}^{3} \cdot \mathrm{d}^{-1}\end{array}$ \\
\hline $\mathrm{E}$ & $\begin{array}{l}\text { Gradeamento; flotação por ar } \\
\text { dissolvido. }\end{array}$ & $\begin{array}{l}\text { Lagoa aeróbia; } \\
\text { decantador. }\end{array}$ & Operação: $170 \mathrm{~m}^{3} \cdot \mathrm{d}^{-1}$ \\
\hline $\mathrm{F}$ & $\begin{array}{l}\text { Gradeamento; equalização; } \\
\text { flotação por ar dissolvido. }\end{array}$ & N.I.* & $\begin{array}{l}\text { Operação: } 9 \mathrm{~m}^{3} \cdot \mathrm{h}^{-1}, \mathrm{em} \\
\text { bateladas. }\end{array}$ \\
\hline $\mathrm{G}^{* *}$ & $\begin{array}{l}\text { Separadores estáticos primário } \\
\text { e secundário; flotação por ar } \\
\text { dissolvido; }\end{array}$ & $\begin{array}{l}\text { Lagoa aerada; } \\
\text { decantador. }\end{array}$ & Operação: $6 \mathrm{~m}^{3} \cdot \mathrm{h}^{-1}$ \\
\hline $\mathrm{H}$ & $\begin{array}{l}\text { Gradeamento; Caixa de } \\
\text { gordura; }\end{array}$ & $\begin{array}{l}\text { Lagoa anaeróbia; lagoa } \\
\text { facultativa. }\end{array}$ & N.I.* \\
\hline I & $\begin{array}{l}\text { Gradeamento; caixa de } \\
\text { gordura. }\end{array}$ & $\begin{array}{l}\text { Filtro anaeróbio; lagoa } \\
\text { de polimento. }\end{array}$ & N.I.* \\
\hline $\mathrm{J}$ & $\begin{array}{l}\text { Gradeamento; caixa de } \\
\text { gordura; decantador. }\end{array}$ & $\begin{array}{l}\text { Reator UASB; filtro } \\
\text { anaeróbio. }\end{array}$ & $\begin{array}{l}\text { Projeto: } 15 \mathrm{~m}^{3} \cdot \mathrm{d}^{-1} \\
\text { Operaçãa: } 12 \mathrm{~m}^{3} \cdot \mathrm{d}^{-1}\end{array}$ \\
\hline K & $\begin{array}{l}\text { Gradeamento; caixa de } \\
\text { gordura; decantador. }\end{array}$ & $\begin{array}{l}\text { Reator anaeróbio; filtro } \\
\text { anaeróbio. }\end{array}$ & $\begin{array}{l}\text { Projeto: } 10 \mathrm{~m}^{3} \cdot \mathrm{d}^{-1} \\
\text { Operação: } 10 \mathrm{~m}^{3} \cdot \mathrm{d}^{-1}\end{array}$ \\
\hline $\mathrm{L}$ & $\begin{array}{l}\text { Gradeamento; caixa de } \\
\text { gordura; decantador. }\end{array}$ & $\begin{array}{l}\text { Filtro anaeróbio; } \\
\text { sumidouros. }\end{array}$ & $\begin{array}{l}\text { Operação: } 3 \mathrm{a} \\
4 \mathrm{~m}^{3} \cdot \mathrm{d}^{-1}\end{array}$ \\
\hline M & $\begin{array}{l}\text { Gradeamento; caixa de } \\
\text { gordura; Decantador. }\end{array}$ & $\begin{array}{l}\text { Reator anaeróbio; Filtro } \\
\text { anaeróbio. }\end{array}$ & $\begin{array}{l}\text { Projeto: } 10 \mathrm{~m}^{3} \cdot \mathrm{d}^{-1} \\
\text { Operação: } 10 \mathrm{~m}^{3} \cdot \mathrm{d}^{-1}\end{array}$ \\
\hline $\mathrm{N}$ & $\begin{array}{l}\text { Gradeamento; Caixa de } \\
\text { gordura; decantador. }\end{array}$ & $\begin{array}{l}\text { Reator anaeróbio; Filtro } \\
\text { anaeróbio. }\end{array}$ & $\begin{array}{l}\text { Projeto: } 15 \mathrm{~m}^{3} \cdot \mathrm{d}^{-1} \\
\text { Operação: } 15 \mathrm{~m}^{3} \cdot \mathrm{d}^{-1}\end{array}$ \\
\hline
\end{tabular}

*N.I.: Não informado ou não existente.

** Apenas a empresa $G$ possui etapa terciária em sua estação de tratamento de efluentes, composta por filtração e desinfecção após o sistema de lagoas.

Fonte: Pesquisa de Campo (2015). 
Observou-se nos dados coletados que entre as empresas pesquisadas apenas uma utilizava processos estritamente físicos/físico-químicos no tratamento de seus efluentes. Todas as demais adotam conjugação entre processos físicos e/ou físicoquímicos como pré-tratamento e tratamento primário, e processos microbiológicos como tratamento secundário dos efluentes. Também se verificou que apenas uma das empresas utiliza tratamento em nível terciário ao efluente, com uma etapa de filtração como polimento seguido de desinfecção. Fica evidente a ampla predominância de processos anaeróbios aplicados como tratamento secundário, sendo que apenas três empresas utilizam vias aeróbias no tratamento dos seus efluentes. Vantagens quanto à aplicação dos processos anaeróbios já foram citadas, como baixo consumo de energia, baixa demanda de espaço físico para instalação e baixa geração de lodo quando comparado aos sistemas aeróbios de tratamento de efluentes, podendo ser estes fatores determinantes na escolha desta via para tratamento dos efluentes.

A utilização de sistemas de lagoas (aeróbias, anaeróbias e facultativas) também se apresentou bastante comum, com sete empresas utilizando esta tecnologia nos seus processos. Sistemas de lagoas apresentam baixa complexidade, tanto construtiva quanto operacional, sendo boa alternativa para empresas que não apresentam mão de obra qualificada alocada especificamente ao tratamento dos seus efluentes, e têm sido utilizadas como tratamento principal ou dando polimento ao mesmo.

Deve-se salientar que todas as empresas pesquisadas declararam não encaminhar o soro de queijo gerado no seu processo produtivo para a estação de tratamento de efluentes. Das 14 empresas pesquisadas 11 afirmaram destinar o soro de queijo para alimentação animal, duas combinam destinação para alimentação animal e comercialização, e uma não apresenta geração de soro em suas atividades.

Os poluentes presentes no soro da produção de queijo não devem ser encaminhados à estação de tratamento de efluentes por serem os mais dificilmente biodegradáveis. À exceção do soro, todos os demais efluentes podem ser tratados conjuntamente, incluindo aqueles com presença de detergentes e desinfetantes (JANCZUKOWICZ; ZIELINSKI; DEBOWSKI, 2008). Assim sendo, todas as empresas destinam o soro do seu processo de forma adequada, de acordo com as informações por elas repassadas, não encaminhando à estação de tratamento de efluentes. 


\subsection{EFICIÊNCIAS OPERACIONAIS DO TRATAMENTO DE EFLUENTES DAS EMPRE- SAS PESQUISADAS}

A FATMA (Fundação Estadual do Meio Ambiente do Estado de Santa Catarina), através da sua Instrução Normativa $n^{\circ} 04$ (FATMA, 2014), determina que as empresas que se dediquem a "preparação do leite e fabricação de produtos de laticínios" são atividades às quais se exige a realização de Estudo Ambiental Simplificado para seu licenciamento ambiental. De acordo com a Instrução Normativa n ${ }^{\circ} 04$ (FATMA, 2014), é responsabilidade da empresa a identificação dos potenciais impactos ambientais decorrentes das suas atividades, bem como as medidas mitigadoras a estes impactos. É também responsabilidade da empresa definir os programas ambientais de controle e/ou monitoramento dos impactos ambientais gerados pelas suas atividades e da eficiência das medidas mitigadoras aplicadas. Uma vez elaborados os programas ambientais de mitigação/monitoramento dos impactos decorrentes da atividade, o mesmo é apresentado à FATMA que delibera sobre a viabilidade das medidas apresentadas.

As empresas A e L empregam sumidouros no sistema de tratamento de seus efluentes. Assim sendo, não há dados históricos para os parâmetros ambientais dos efluentes para análise, uma vez que não são realizadas coletas para monitoramento de suas características físico-químicas já que seus programas de controle e/ou monitoramento dos impactos ambientais não prevêem isso. A empresa $\mathrm{C}$ teve seu sistema de lagoas superdimensionado para o montante de efluente gerado. Desta forma, o efluente enviado às lagoas é perdido por evaporação antes mesmo de completar o volume total do sistema. Assim, nenhum efluente é despejado no corpo receptor, de forma que não são realizadas análises periódicas que possam demonstrar a eficiência do processo. $\mathrm{A}$ empresa $\mathrm{H}$ não disponibilizou dados referentes ao histórico das análises do seu sistema de tratamento.

Para as demais empresas, o histórico de monitoramento fornecido foi das sete últimas análises realizadas para as empresas D, F, J, K, M e N. As empresas B, E, $\mathrm{G}$ e I forneceram resultados referentes às três últimas análises realizadas.

Todas as empresas pesquisadas têm periodicidade trimestral na realização das análises das condições de lançamento dos efluentes aos corpos receptores. Para todas as empresas pesquisadas os parâmetros físico-químicos avaliados para fins de monitoramento ambiental do lançamento de efluentes nos corpos receptores são os que se seguem no Quadro 2. Tanto a periodicidade quanto os parâmetros a 
serem avaliados são determinados pela empresa no processo do seu licenciamento, conforme definido na Instrução Normativa nº 04 da FATMA (FATMA, 2014).

Quadro 2. Padrões para lançamento de efluentes de Laticínios em SC

\begin{tabular}{|c|c|c|}
\hline Parâmetro & Padrão de lançamento & Legislação \\
\hline $\mathrm{DBO}_{5}, 20^{\circ} \mathrm{C}$ & $\begin{array}{c}\text { Máx. } 60 \text { mg.L.-1 ou remoção } \\
\text { mínima de } 80 \% \text { da carga } \\
\text { poluidora }\end{array}$ & $\begin{array}{l}\text { Lei estadual } 14.675 \text {, de } \\
13 \text { de abril de } 2009^{\mathrm{a}} \text {. }\end{array}$ \\
\hline $\mathrm{pH}$ & Entre 6,0 e 9,0 & $\begin{array}{l}\text { Lei estadual } 14.675 \text {, de } \\
13 \text { de abril de } 2009^{\mathrm{a}} \text {. }\end{array}$ \\
\hline $\begin{array}{c}\text { Óleos vegetais e gorduras } \\
\text { animais }\end{array}$ & Máx. $30 \mathrm{mg} . \mathrm{L}^{-1}$ & $\begin{array}{l}\text { Lei estadual } 14.675 \text {, de } \\
13 \text { de abril de } 2009^{\mathrm{a}} \text {. }\end{array}$ \\
\hline Sólidos sedimentáveis & $\begin{array}{c}1 \text { mL.. } \mathrm{L}^{-1} \text { e ausência quando } \\
\text { o corpo receptor for lago ou } \\
\text { lagoa }\end{array}$ & $\begin{array}{c}\text { Resolução Conama } \\
\text { número } 430, \text { de } 13 \text { de } \\
\text { maio de } 2011^{\mathrm{b}} \text {. }\end{array}$ \\
\hline
\end{tabular}

Fonte: a (SANTA CATARINA, 2009); b (BRASIL, 2011).

Todas as empresas pesquisadas lançam seus efluentes no rio Braço do Norte, com exceção da empresa $\mathrm{B}$, que lança seus efluentes em um afluente do rio Capivari. Estes dois rios são os principais afluentes do rio Tubarão, que dá nome à bacia hidrográfica onde está inserido: bacia hidrográfica do rio Tubarão e Complexo Lagunar. Os rios Braço do Norte e Capivari formam duas sub-bacias da bacia hidrográfica do rio Tubarão que levam os seus nomes.

$\mathrm{Na}$ Tabela 1, são apresentados os resultados alcançados pelas estações de tratamento de efluentes pesquisadas em relação às exigências das legislações aplicáveis, de acordo com as informações fornecidas pelas próprias empresas, ou seus representantes. As variações nas eficiências dos sistemas ao longo do tempo foram comentadas em termos de coeficiente de variação (C.V.).

Tabela 1. Remoção média percentual de matéria orgânica em $\mathrm{DBO}_{5}$

$\begin{array}{llllllllllll}\text { Empresa } & \text { B } & \text { D } & \text { E } & \text { F } & \text { G } & \text { I } & \text { J } & \text { K } & \text { M } & \text { N }\end{array}$

\begin{tabular}{ccccccccccc}
\hline $\begin{array}{c}\text { Remoção média da DBO } \\
(\%)\end{array}$ & 91,27 & 89,00 & 95,30 & 89,27 & 81,98 & 91,42 & 89,18 & 89,56 & 88,86 & 87,30 \\
\hline C.V. (\%) & 8,15 & 5,86 & 2,25 & 4,54 & 1,94 & 4,26 & 7,68 & 7,42 & 7,18 & 7,14 \\
\hline
\end{tabular}

Fonte: Pesquisa de Campo (2015). 
Observa-se que todas as empresas se encontram de acordo com o que exige a legislação ambiental, lei estadual 14.675 (SANTA CATARINA, 2009), ou seja, remoção da DBO acima de $80 \%$. Também se observou que os desempenhos apresentados pelos sistemas são bastante estáveis, de forma que o maior coeficiente de variação encontrado foi para a empresa $\mathrm{B}$, com valor de $8,15 \%$.

Para remoção de óleos e graxas (O.G.), os resultados médios obtidos por empresa estão apresentados na Tabela 2.

Tabela 2. Concentração média de óleos e graxas residuais no efluente tratado

\begin{tabular}{ccccccccccc}
\hline Empresa & B & D & E & F & G & I & J & K & $M$ & N \\
\hline $\begin{array}{c}\text { Residual médio de } \\
\left.\text { O.G. (mg.L } L^{-1}\right)\end{array}$ & 12,73 & 21,34 & 2,27 & 13,21 & 14,80 & 10,57 & 17,33 & 22,59 & 18,67 & 23,49 \\
\hline C.V. (\%) & 16,18 & 34,80 & 20,38 & 43,48 & 76,97 & 16,29 & 51,01 & 108,60 & 44,50 & 31,78
\end{tabular}

Fonte: Pesquisa de Campo (2015).

Apesar de todos os valores médios de residual de O.G. estarem em conformidade com o exigido pela legislação, observou-se que os efluentes de algumas das empresas pesquisadas apresentaram concentrações para este parâmetro acima dos limites permitidos pela lei estadual 14.675 (SANTA CATARINA, 2009), de 30 mg. $L^{-1}$, em pelo menos uma das análises apresentadas. Foram encontrados valores de lançamento acima do permitido para as empresas D (36,00 mg.L $\left.\mathrm{L}^{-1}\right), \mathrm{J}$ (36,50 mg.L: $\left.{ }^{1}\right)$, K (78,00 mg. $\left.\mathrm{L}^{-1}\right)$, M (36,00 mg. $\left.\mathrm{L}^{-1}\right)$ e N (40,00 mg. $\left.\mathrm{L}^{-1}\right)$. Com base nos resultados das análises fornecidos pelas empresas, observou-se que a empresa $\mathrm{E}$ apresentou a

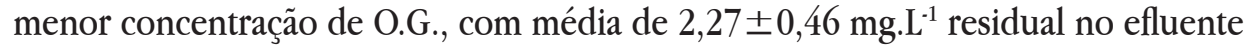
tratado, mesmo com coeficiente de variação de $20,38 \%$, que foi tão alto pelo baixo valor médio do parâmetro avaliado.

Todas as empresas que apresentaram residuais de óleos e graxas acima do permitido no efluente utilizam caixa de gordura para remoção deste contaminante. Assim sendo, mesmo com utilização de um equipamento de operação simples, não foi alcançada a eficiência necessária. Esse fato pode ser explicado pela ocorrência de defeito do equipamento ou formação de emulsão do óleo na água. Elevada temperatura, presença de substâncias detergentes, $\mathrm{pH}$ elevado ou ocorrência simultânea destes fatores podem favorecer esta condição.

A alta variabilidade nos níveis de O.G. lançados pela mesma empresa em diferentes análises é evidenciada por valores de C.V. que atingem 108,60\% e 76,97\% 
para as empresas K e G, respectivamente, demonstrando baixo nível de controle do processo e, consequentemente, de gestão dos seus aspectos ambientais relacionados aos recursos hídricos.

Os resultados das análises de $\mathrm{pH}$ para os efluentes tratados pelas empresas se encontram representados na Tabela 3.

Tabela 3. Valores médios de $\mathrm{pH}$ do efluente após tratamento

\begin{tabular}{ccccccccccc}
\hline Empresa & B & D & E & F & G & I & J & K & M & N \\
\hline pH médio do efluente tratado & 6,71 & 6,48 & 7,04 & 6,86 & 7,18 & 6,53 & 6,65 & 6,62 & 6,70 & 6,45 \\
\hline C.V. (\%) & 6,92 & 5,38 & 10,91 & 8,86 & 5,39 & 10,46 & 5,16 & 4,83 & 6,49 & 5,73 \\
\hline
\end{tabular}

Fonte: Pesquisa de Campo (2015).

Observa-se, novamente, a exemplo das concentrações de O.G., que os valores médios das análises de $\mathrm{pH}$ que as empresas forneceram atendem ao exigido pela legislação pertinente. Contudo, as empresas $\mathrm{F}$ e M apresentaram valores de pH para o efluente tratado de 5,61 e 5,96, respectivamente, em uma oportunidade cada, caracterizando que o efluente não estaria adequado ao lançamento no corpo receptor. Os maiores valores de C.V. foram encontrados para as empresas E e I, 10,91 e 10,46\%, respectivamente, apontando menor variação dos valores de $\mathrm{pH}$ entre as análises, quando comparado ao parâmetro O.G. Contudo, ainda se verifica a falta de controle dos parâmetros relativos à qualidade do efluente destinado ao corpo receptor, evidenciado pelo lançamento de efluente fora da faixa ideal de $\mathrm{pH}$, que é entre 6,0 e 9,0.

Os resultados fornecidos pelas empresas para sólidos sedimentáveis (S.S.) dos seus efluentes tratados estão listados na Tabela 4 :

Tabela 4. Valores médios de sólidos sedimentáveis presentes no efluente tratado

\begin{tabular}{ccccccccccc}
\hline Empresa & $\mathrm{B}$ & $\mathrm{D}$ & $\mathrm{E}$ & $\mathrm{F}$ & $\mathrm{G}$ & $\mathrm{I}$ & $\mathrm{J}$ & $\mathrm{K}$ & $\mathrm{M}$ & $\mathrm{N}$ \\
\hline $\begin{array}{c}\text { Volume médio de S.S. } \\
\text { (mL.L } \text { - }^{\text {) }}\end{array}$ & 0,07 & 0,20 & 0,10 & $0,00^{*}$ & 0,07 & 0,03 & 0,39 & 0,46 & 0,14 & 0,14 \\
\hline C.V. (\%) & 0,00 & 141,42 & 0,00 & 0,00 & 106,07 & 212,13 & 348,32 & 371,23 & 55,08 & 55,08 \\
\hline
\end{tabular}

* Em todas as análises os valores encontrados foram inferiores a $0,10 \mathrm{~mL} . \mathrm{L}^{-1}$.

Fonte: Pesquisa de Campo (2015). 
Observou-se que a grande maioria das empresas atende aos padrões de lançamento para S.S., que é de no máximo 1,00 mL.L-1 quando o corpo receptor é um rio, caso aplicável a todas as empresas pesquisadas. Observaram-se valores de S.S. acima do permitido pela resolução Conama 430 (BRASIL, 2011), apenas nas empresas J (2,00 mL.L $\left.{ }^{-1}\right)$ e K (2,50 mL.L $\left.\mathrm{L}^{-1}\right)$, em uma oportunidade cada. A exemplo dos outros parâmetros analisados observou-se que a média dos valores fornecidos pelas empresas sempre atendem ao exigido pela legislação.

Nenhuma das empresas realiza o monitoramento do montante de nutrientes que lança ao corpo receptor. Uma vez que o efluente de laticínios é fonte simultânea de fósforo e nitrogênio ao ambiente seria muito pertinente a realização deste monitoramento por serem estes nutrientes causadores de grandes danos ao meio aquático, notadamente a eutrofização do corpo receptor (CARVALHO; PRAZERES; RIVAS, 2013).

Percebe-se que o monitoramento ambiental, realizado pelas empresas, aponta alguns casos em que os efluentes são lançados fora dos padrões permitidos por lei. Ressalta-se, ainda, que as análises dos parâmetros especificados para o monitoramento ambiental são realizadas trimestralmente. Desta forma, embora os resultados das análises possam apresentar valores de acordo com o exigido pelas legislações acima citadas, é possível que no período que decorre entre uma coleta e outra haja despejo de efluentes fora dos padrões preconizados sem que seja detectada a não conformidade.

\subsection{DADOS REFERENTES À GESTÃO AMBIENTAL NAS EMPRESAS}

De todas as empresas pesquisadas, apenas as empresas E e F declararam ter pessoal internamente qualificado na operação do seu sistema de tratamento de efluentes, além da responsabilidade técnica pela gestão dos seus aspectos ambientais ser exercida também por pessoal interno. A empresa $G$ declarou ter pessoal internamente qualificado apenas para a operação do sistema de tratamento de efluentes, sendo que a responsabilidade técnica pela sua eficiência e pelo monitoramento da qualidade dos despejos é terceirizada.

Todas as demais empresas trabalham com consultoria externa na gestão de seus aspectos ambientais, em que tanto o monitoramento das condições do 
efluentes quanto a responsabilidade técnica pelas suas condições são exercidas por terceiros, além de declararem não possuir pessoal qualificado na operação da estação de tratamento de efluentes. Apenas as empresas G e E declararam fazer o reúso da água tratada no seu processo produtivo.

\section{CONSIDERAÇÕES FINAIS}

Diante da pesquisa realizada, é possível concluir que as empresas utilizam sistema primário de tratamento de efluentes baseados em métodos predominantemente físicos de separação dos contaminantes. O tratamento em nível secundário (biológico) apresenta predominância de sistemas anaeróbios. Sistemas de lagoas, foram utilizados por metade das empresas, o que pode ser reflexo da ausência de pessoal tecnicamente capacitado na operação do tratamento de efluentes, em vista da sua baixa complexidade operacional.

Quanto à eficiência dos sistemas de tratamento de efluentes foram encontrados valores fora dos limites estabelecidos pelos órgãos ambientais para parâmetros como óleos e graxas, pH e sólidos sedimentáveis, demonstrando falhas na gestão dos aspectos ambientais relacionados à atividade, além de não serem considerados aspectos importantes da atividade como lançamento de nutrientes ao corpo receptor. O reúso da água é pouco realizado pelas empresas estudadas.

Quanto à gestão ambiental observou-se a carência de pessoal capacitado atuando interna e continuamente nas empresas, o que pode ser determinante nos problemas identificados com a realização deste trabalho.

\section{REFERÊNCIAS}

AMINI, M.; YOUNESI , H.; LORESTANI, A. A. Z.; NAJAFPOUR, G. Determination of optimum conditions for dairy wastewater treatment in UAASB reactor for removal of nutrients. Bioresource Technology, v.145, p. 71-79, 2013.

BABATOLA, J. O.; OLADEPO, K. T.; LUKMAN, S.; OLARINOYE, N. O.; OKE, I. A. Failure analysis of a dissolved air flotation treatment plant in a dairy industry. Journal of Failure Analysis and Prevention, v.11, p.110-122, 2011. 
BRASIL. CONSELHO NACIONAL DO MEIO AMBIENTE. Resolução No 430, de 13 de Maio de 2011. Dispõe sobre as condições e padrões de lançamento de efluentes, complementa e altera a Resolução $\mathrm{n}^{\circ} 357$, de 17 de março de 2005. Diário Oficial da União $\mathrm{n}^{0}$ 92. Brasília, DF, 16 de Maio de 2011.

CARVALHO, F.; PRAZERES, A. R.; RIVAS, J. Cheese whey wastewater: characterization and treatment. Science of the Total Environment, v. 445-446, p. 385-396, 2013.

DEMIREL, B.; YENIGUN, O.; ONAY, T. T. Anaerobic treatment of dairy wastewaters: a review. Process Biochemistry, v. 40, n. 8, p. 2583-2595, 2005.

DEZOTTI, M. Processos e técnicas para o Controle Ambiental de Efluentes Líquidos. Rio de Janeiro: E-papers, 2008. 360 p.

DVARIONIENE, J.; KRUOPIENE, J.; STANKEVICIENE, J. Application of cleaner technologiesin milk processing industry to improve the environmental efficiency. Clean Technologies and Environmental Policy, v. 14, p. 1037-1045, 2012.

EPAGRI/CEPA. Síntese Anual da Agricultura de Santa Catarina 2014-2015. Florianópolis: EPAGRI/CEPA, 2015, 153p.

FUNDAÇÃO DO MEIO AMBIENTE DO ESTADO DE SANTA CATARINA - FATMA. Instrução Normativa $\mathbf{n}^{\circ}$ 04: Atividades industriais. Abril, 2014.

INSTITUTO BRASILEIRO DE GEOGRAFIA E ESTATÍSTICA. Estatística da produção agropecuária Junho de 2015. Disponível em: < http://www.ibge.gov.br/home/ estatistica/indicadores/agropecuaria/producaoagropecuaria/abate-leite-couroovos_201501_publ_completa.pdf > Acesso em 07/10/2015.

JANCZUKOWICZ, W.; ZIELINSKI, M.; DEBOWSKI, M. Biodegradability evaluation of dairy effluents originated in selected sections of dairy production. Bioresource technology, v. 99, p 4199-4205, 2008.

MENDES, P. R. A.; ZIZAS, L. N.; FARIA, L. F. F. Utilização de processo oxidativo avançado do tipo foto-fenton na degradação de efluente da produção de queijos. 
In: XX CONGRESSO BRASILEIRO DE ENGENHARIA QUÍMICA - COBEQ, 20., 2014, Florianópolis. Anais... v. 1, 2014, p. 24.674. Disponível em: < https://proceedings. galoa.com.br/cobeq/trabalhos/utilizacao_de_processo_oxidativo_avancado_do_ tipo_foto-fenton_na_degradacao_de_efluente_da_producao $>$. Acesso em: 25 nov. 2015.

SANTA CATARINA. Lei $\mathrm{n}^{0}$ 14.675, de 13 de Abril de 2009. Institui o código estadual do meio ambiente e estabelece outras providências. Diário Oficial do Estado de Santa Catarina, Florianópolis, SC, 14 de Abril de 2009.

SEBRAE/SC. Santa Catarina em números. Florianópolis: SEBRAE/SC, 2013, 150p.

SHETE, B. S.; SHINKAR, N. P. Comparative study of various treatments for dairy industry wastewater. IOSR Journal of Engineering. v.3, n. 8, p.42-47, 2013.

Recebido em: 18 de dezembro de 2015 Aceito em: 06 de outubro de 2016 